\title{
High- Temperature NDIR- Gas- Measurement- Module
}

\author{
A. Magi, H. Klaubert, S. Biermann, P. Sachse, S. Schneider, J. Kluge \\ Micro-Hybrid Electronic GmbH, Heinrich-Hertz-Str. 8, 07629 Hermsdorf \\ infrared@micro-hybrid.de
}

\begin{abstract}
:
The poster descripts the new Micro-Hybrid high temperature gas measurement module for carbon dioxide. The module based on the well known NDIR measurement principle. The basics of this concept is descript in the text. Furthermore, Micro-Hybrid special infrared components line for harsh environments is presented. The MEMS emitter and highly sensitive detectors are used for high temperatures up to $190^{\circ} \mathrm{C}$ and also for low temperat ures down to $-50{ }^{\circ} \mathrm{C}$. This wide temperature range is possible through special packaging technologies like soldering and welding. The prototype bases customized gas sensors. Concluding, the sensor parameters are listed.
\end{abstract}

Key words: high temperature, NDIR, sensor, gas analysis, CO2,

\section{Introduction}

NDIR-based sensors can be used to detect or control gas concentration in any kind of application. The advantages are high reliability, long term stability and accuracy. The sensor withstands temperatures up to $200{ }^{\circ} \mathrm{C}$ and can measure gas concentrations up to $190^{\circ} \mathrm{C}$. It can be used to determine gas concentration at high temperatures e.g. in chemical or biochemical process control or in applications where the detector is cyclic exposed high temperatures.

\section{Measurement principle}

The module based on the NDIR (non dispersive infrared) gas measurement principle is a well known and established gas analysis technique. The configuration of the module is designed for measuring $\mathrm{CO} 2$ in high concentrations. Fig. 1 shows a principle picture of the module. The measuring chamber is filled with the gas to be investigated. Infrared radiation delivered by a MEMS based IR- source passes through the gas and generates a signal voltage in the thermopile infrared detector.

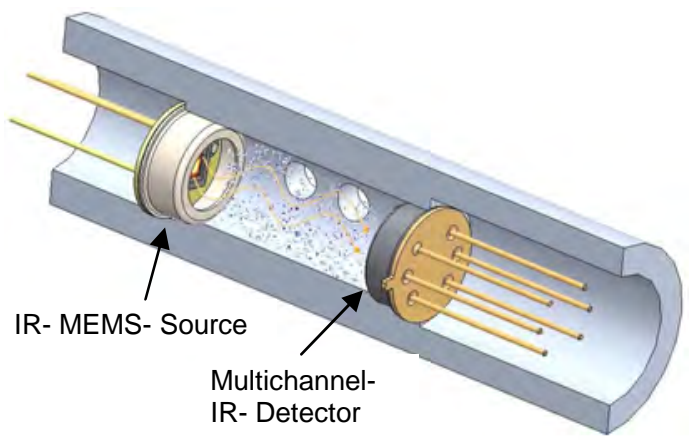

Fig. 1 Principle of the gas measuring chamber
The detector is assembled with narrow band pass filters. The CWL of the filters is fitted to their specific transmission wavelength of the gas which should be detected. The developed gas measurement module contains a special multichannel thermopile detector depending on the measured gases. In fig. 2 the absorption of $\mathrm{CO} 2$ is shown in dependence of the wavelength at room temperature under normal pressure. In the same pictures the transmission curve of the used infrared filters is shown. One of the canals of the detector has a filter which is not coincident with the absorption wavelengths. It is used as a reference channel to correct possible changes of the intensity of the source that can occur by aging effects or by the influence of dust and smoke. The infrared source is switched on and off periodically. In this way disturbing offset voltages can be eliminated by measuring only the signal differences.

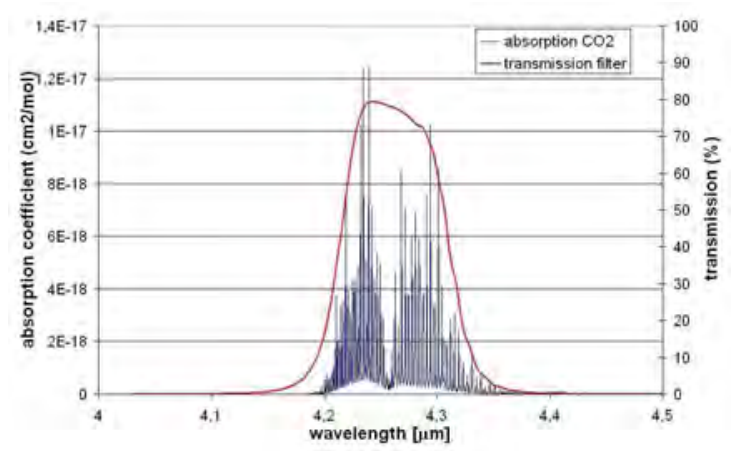

Fig. 2 Absorption of $\mathrm{CO} 2$ in dependence on the wavelength and transmission curves of the used filters 


\section{Sensor concept}

The main feature of the gas measurement module is its ability to withstand high temperatures up to $200^{\circ} \mathrm{C}$. Its performance is a feature based on MHE own infrared components. The thermopile detector based on high effective $\mathrm{BiSb} / \mathrm{Sb}$ thermocouples which enables a high sensitivity also at high temperatures. The MEMS infrared emitter based on temperature stable amorphous diamond like carbon coatings. This enables high membrane temperatures as well as high radiation intensities. The IR- emitter and the IRdetector are assembled in special technologies like soldering and welding to ensure the hermetic housing at these high temperatures.

The real hermetic packaging technologies from Micro-Hybrid guarantee long term stability of infrared components used in harsh environments. Contrary to adhesion joints, there is no permeation into the case based on soldered and welded joints. Backfilling inert gases, like nitrogen, make this component useful in cold environments down to $-50{ }^{\circ} \mathrm{C}$. Furthermore it is possible to tune the sensor and emitter parameters with different backfill gases. For example the sensitivity of the IRdetector can be increased by backfilling an inert gas with a low thermal conductivity. On the same way the power consumption of the IRemitters can be decreased.

Basically the electronic evaluation circuit is separated from the gas measurement cell. The electrical connections are made by a high temperature cable that contains twisted and shielded wires. The distance between electronic and measurement cell can be up to $20 \mathrm{~cm}$ without influencing the signal to noise. If a long distance between measuring point and electronic unit is necessary, the measuring cell contains a high temperature pre-amplification based on LTCC technology. Figure 3 shows the developed high temperature gas measurement module.

\section{Specification of the Demonstration}

\begin{tabular}{|c|c|}
\hline measuring gas: & $\mathrm{CO} 2$ \\
\hline $\begin{array}{l}\text { measuring range } \\
\text { CO2: }\end{array}$ & $0 \ldots 20$ vol\% \\
\hline $\begin{array}{l}\text { measuring range } \\
\text { temperature (inside } \\
\text { the sensor): }\end{array}$ & $0 \ldots 200^{\circ} \mathrm{C}$ \\
\hline accuracy: & \pm 0.2 vol $\%+2 \%$ of read. \\
\hline $\begin{array}{l}\text { additional errors: } \\
\text { (air pressure } \\
\text { measured in } \\
\text { external electronic) }\end{array}$ & $\begin{array}{l}<2 \% \text { of the measured } \\
\text { value for temperature and } \\
\text { atmospheric pressure }\end{array}$ \\
\hline response time: & $<30 s$ \\
\hline heat up time: & $<15 \min$ \\
\hline $\begin{array}{l}\text { temperature range } \\
\text { sensor: }\end{array}$ & $-25 \ldots+200^{\circ} \mathrm{C}$ \\
\hline $\begin{array}{l}\text { temperature range } \\
\text { ext. electronics: }\end{array}$ & $-25 \ldots+85^{\circ} \mathrm{C}$ \\
\hline interfaces: & $\begin{array}{l}4-20 \mathrm{~mA} \\
0-1 \mathrm{~V}, 0-10 \mathrm{~V} \\
\mathrm{RS} 232, \mathrm{CAN}\end{array}$ \\
\hline supply voltage: & $12 \mathrm{~V} \pm 1 \mathrm{~V} \max .2 \mathrm{~W}$ \\
\hline
\end{tabular}

\section{Conclusion}

Gas measuring modules normally work around room temperature. This demonstration model is the basis for customized gas measurement cells and shows Micro-Hybrid's competence in high temperature and hermetic packaging technologies. The described module is cost effective and best suited for high temperature field applications, undoubtedly finding its place in the market of gas measurement modules.

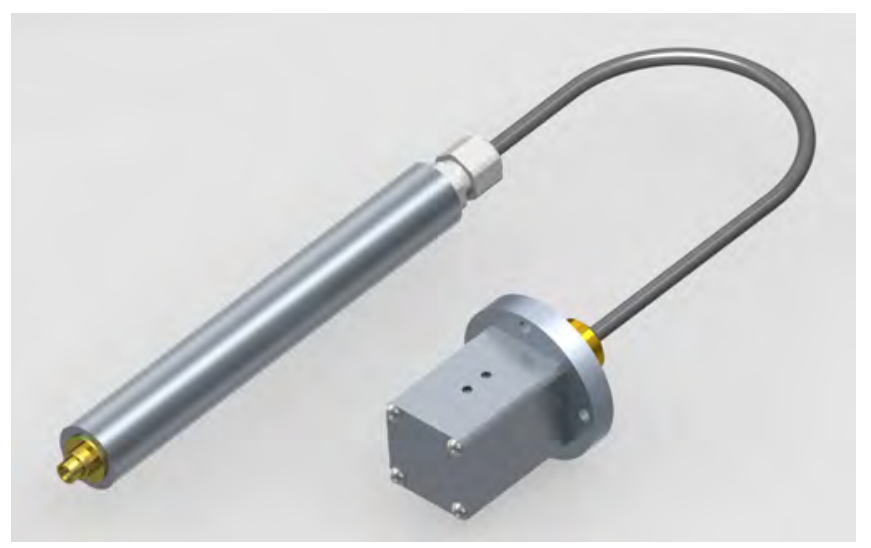

Fig. 3 HT CO2 measurement cell with extern signal conditional electronic 